Case Report

\title{
Massive Gastric Hemorrhage due to Dieulafoy's Lesion in a Preterm Neonate: A Case Report and Literature Review of the Lesion in Neonates
}

\author{
Christos Salakos, ${ }^{1,2}$ Panayiota Kafritsa, ${ }^{3}$ Yvelise de Verney, ${ }^{2}$ \\ Ariadni Sageorgi, ${ }^{4}$ and Nick Zavras ${ }^{1}$ \\ ${ }^{1}$ Department of Pediatric Surgery, ATTIKON University Hospital, 1 Rimini Street, Haidari, 12462 Athens, Greece \\ ${ }^{2}$ Department of Pediatric Surgery, "IASO" Maternity and Children's Hospital, 37-39 Kifisias Street, Marousi, 15123 Athens, Greece \\ ${ }^{3}$ Department of Gastroenterology, "IASO” Maternity and Children's Hospital, 37-39 Kifisias Street, Marousi, 15123 Athens, Greece \\ ${ }^{4}$ Neonatal Intensive Care Unit, "IASO" Maternity and Children's Hospital, 37-39 Kifisias Street, Marousi, 15123 Athens, Greece
}

Correspondence should be addressed to Nick Zavras; nzavras@med.uoa.gr

Received 21 February 2015; Revised 14 May 2015; Accepted 24 May 2015

Academic Editor: Denis A. Cozzi

Copyright (c) 2015 Christos Salakos et al. This is an open access article distributed under the Creative Commons Attribution License, which permits unrestricted use, distribution, and reproduction in any medium, provided the original work is properly cited.

Dieulafoy's lesion is an extremely rare cause of upper gastrointestinal bleeding in the neonatal age group. Till now, only 6 cases of Dieulafoy's lesion in neonatal period have been reported in the international literature. Herein, we report an extremely rare case of Dieulafoy's lesion in a preterm neonate.

\section{Introduction}

Dieulafoy's lesion (DL) is a distinct entity characterized by the presence of a large artery located under the muscularis mucosa and usually protruding into the gastric lumen [1]. The lesion accounts for $0.3 \%$ to $6.7 \%$ of the upper gastrointestinal (GI) tract bleeding cases in adults [2]. However, its exact prevalence in the pediatric population is unknown as most published studies concern case reports. In a recent review of the English language literature, the authors identified 28 pediatric cases with DL, among whom there were two full-term neonates and one preterm. All these neonates manifested the disease on the 1st, 3rd, and 4th postnatal day, respectively [3-5].

Herein, we describe a preterm neonate with DL. A brief review on neonatal cases is discussed.

\section{Case Report}

A preterm male neonate was born as twin $\mathrm{B}$ after an IVF pregnancy to a 36-year-old gravida 1 , para 2 mother at $26^{+1}$-week gestation, due to idiopathic preterm labor. His birth weight was $1010 \mathrm{~g}$ (90th percentile), and his length and head circumference were $34 \mathrm{~cm}$ (50th percentile) and $25.4 \mathrm{~cm}$ (90th percentile), respectively. Apgar scores were 4 at 1 minute and 6 at 5 minutes. The neonate was intubated to increase respiratory efforts and he was transferred to the neonatal intensive care unit (NICU). He remained on mechanical ventilation for 36 days. On day 65 of hospitalization (postconceptual age: $34^{+5}$ weeks, weight $2020 \mathrm{~g}$ ), he presented with a massive oral hematemesis and was transferred to the NICU yet again. On examination, he was pale and displayed mild abdominal distention. Initial laboratory examinations showed hemoglobin of $10 \mathrm{~g} / \mathrm{dL}$ (13.5-19.5 g/dL); hematocrit 29.3\% (40-64\%); WBC 5,050 cells $/ \mu \mathrm{L}(10.000-26000$ cells $/ \mu \mathrm{L})$; and platelet count $190,000 / \mu \mathrm{L}(150,000-400,000 / \mu \mathrm{L})$. The coagulation tests were normal. After a one-blood volume transfusion, esophagogastroduodenoscopy (EGD) was performed with an Olympus GIF-N180 neonatal endoscope, which identified the presence of a big blood clot in the fundus, adherent to the gastroesophageal junction without signs of active bleeding (Figure 1). However, despite the efforts, the blood clot could not be reached even in full retroflexion. A second endoscopy was performed the following day after a massive 
TABLE 1: Published cases of Dieulafoy's lesion in the neonatal age group.

\begin{tabular}{|c|c|c|c|c|c|c|c|c|}
\hline Authors & GA & Sex & Age & Site & Diagnosis & Treatment & Recurrence & Outcome \\
\hline Lee et al. [4] & Full-term & $\mathrm{M}$ & $3 \mathrm{~d}$ & Stomach & Endoscopy & Hemostatic clip & No & Successful \\
\hline Koo et al. [7] & Full-term & M & $1 \mathrm{~d}$ & Stomach & Endoscopy & $\begin{array}{c}\text { Endoscopic } \\
\text { epinephrine injection }\end{array}$ & No & Successful \\
\hline Koo et al. [7] & Full-term & $\mathrm{F}$ & $1 \mathrm{~d}$ & Stomach & Endoscopy & $\begin{array}{c}\text { Endoscopic } \\
\text { epinephrine injection }\end{array}$ & No & Successful \\
\hline Lee et al. [8] & Full-term & $\mathrm{M}$ & $1 \mathrm{~d}$ & Stomach & Endoscopy & Hemostatic clip & No & Successful \\
\hline $\begin{array}{l}\text { Polonkai et al. } \\
{[5]}\end{array}$ & Late preterm & M & $5 \mathrm{~d}$ & Stomach & Endoscopy & Hemostatic clip & No & Death \\
\hline Zavras et al. [3] & Full-term & $\mathrm{M}$ & $1 \mathrm{~d}$ & Stomach & Endoscopy & Thermocoagulation & No & Successful \\
\hline Present case & Preterm & M & $65 \mathrm{~d}$ & Stomach & Laparotomy & Laparotomy & No & Successful \\
\hline
\end{tabular}

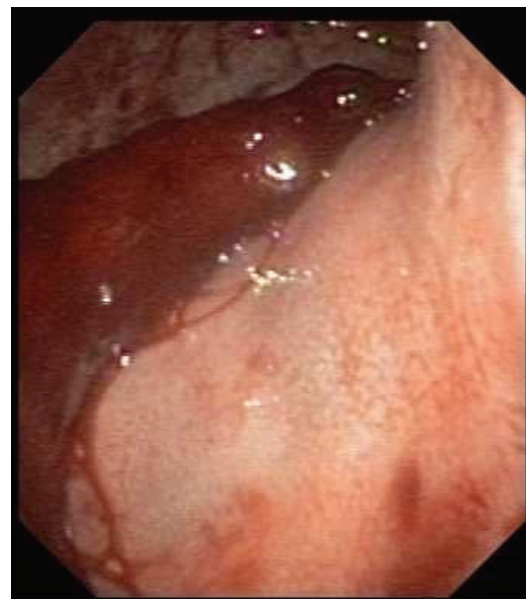

FIGURE 1: A big blood clot adherent to the gastroesophageal junction was seen in the 1st endoscopy. The clot could not be reached by endoscopy.

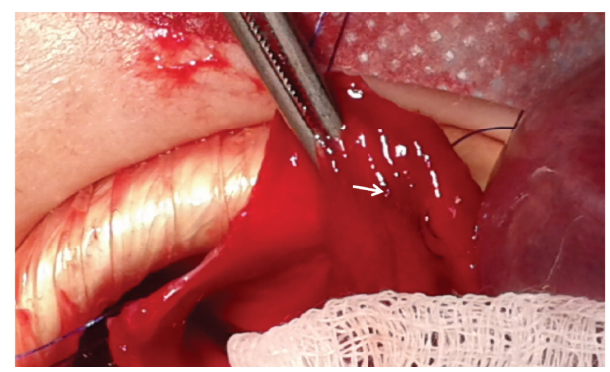

FIGURE 2: A spurting arterial vessel was seen after gastrotomy (white arrow).

hematemesis and a further drop in the levels of hemoglobin and hematocrit $(8.6 \mathrm{~g} / \mathrm{dL}$ and $25.1 \%$, resp.). However, the presence of a pool of blood prevented the endoscope from visualizing the source of bleeding. Again, the site of bleeding could not be approximated. An emergency laparotomy with gastrotomy was carried out which revealed a spurting arterial vessel that was ligated at a distance of less than $3 \mathrm{~cm}$ from the gastroesophageal junction (Figure 2). The infant had an uneventful recovery. No recurrence of bleeding was noted during 8 months of follow-up.

\section{Discussion}

DL lesion is extremely rare in the neonatal age group. Relevant articles in the international literature, dating from the first case reported in 1968 [6] to present, were retrieved from PubMed, SCOPUS, and Medline using the key words Dieulafoy's lesion, caliber persistent artery, neonates, and children. We found only three cases in the English literature [3-5] and another three in the Asian literature [7, 8]. All but one neonate were full-term, with a male/female ratio $5: 1$ (Table 1). To our knowledge, this case is the second to be described in a preterm male neonate.

Although DL was first reported by Gallard in 1884 [9], it carries the name of Dieulafoy who reported the lesion in three patients with upper gastrointestinal bleeding [10]. He called it "exulceratio simplex," characterised by an oval or elliptical shaped acute ulcerative process with dimensions of $2-5 \mathrm{~mm}$. Regardless of the age of the patient, the lesion is usually located in the upper stomach $6 \mathrm{~cm}$ below the esophagogastric mucosa [11], but it can also be found anywhere within the entire GI tract from the esophagus to the rectum, or at sites outside the GI tract, such as the bronchi [12]. In the reviewed cases, including our own, DL was located in the stomach in all neonates (Table 1).

The clinical presentation more commonly includes a painless and massive upper GI hemorrhage, possibly recurrent [12]. Hemodynamic instability may be involved [12]. The pathogenesis of DL is not clearly understood. Among various causes, the hypothesis of a congenital origin seems to be the most acceptable [13]. According to this theory, the bleeding artery maintains its initial diameter as it enters the gastric wall rather than decreasing [13]. This abnormality renders the vessel prone to massive bleeding. The congenital anomaly is supported by reported cases of neonates.

Endoscopy is the first method of diagnosis in DL, and the diagnostic criteria are well established [14]. In cases of gastric DL in both the adult and pediatric population, the success rate ranges between $70 \%$ and $80 \%[11,14]$, though repeated endoscopies may be required to establish the diagnosis [14]. Similarly, in the cases listed here (Table 1), the success rate 
of endoscopic diagnosis was as high as $85.7 \%$. However, in our case, two endoscopic investigations failed to localize the source of bleeding due to the presence of a clot in the first endoscopy and active bleeding in the second; thus, a gastrotomy was performed to identify the source of bleeding.

So far, there is not a general agreement on the management of DL [14]; hence, the choice of treatment relies on the location of the DL and suitable skills. It is worth saying that advancements in endoscopic procedures, even in neonates, have limited the use of surgical intervention. A success rate reaching 98\% has been reported with various endoscopic modalities, including the hemoclip, injection of sclerosants, thermocoagulation, or band ligation $[3,15]$. In neonatal case series (Table 1), successful hemostasis was achieved with a hemoclip in three patients, injection of epinephrine in two patients, and thermal coagulation in one patient. Recently, surgical intervention was reserved only for cases deemed unmanageable with endoscopic procedures [3]. In our case, the site of the DL was very close to the gastroesophageal junction and was covered with blood. Consequently, an open laparotomy was decided. No recurrence was noted in our listed cases, and death was reported in just one patient [5] due to coexistent lesions.

The present case illustrates a very rare case of DL in a preterm neonate. Although endoscopy is considered the first diagnostic tool of intervention, in the paediatric population, the management of DL may be very difficult. The lack of fine endoscope and the tiny size of the stomach pose a challenge for endoscopic procedures. Notably, in the cases of recurrent massive bleeding of upper GI, an open approach should be promptly carried out to determine and treat DL.

\section{Conflict of Interests}

The authors declare that there is no conflict of interests regarding the publication of this paper.

\section{References}

[1] H. L. Karamanoukian, D. T. Wilcox, E. I. Hatch, R. Sawin, and P. L. Glick, "Dieulafoy's disease in infants," Pediatric Surgery International, vol. 9, no. 8, pp. 585-586, 1994.

[2] H. F. Reilly III and F. H. Al-Kawas, "Dieulafoy's lesion: diagnosis and management," Digestive Diseases and Sciences, vol. 36, no. 12, pp. 1702-1707, 1991.

[3] N. Zavras, C. Siafakas, G. Pergamalis, Y. de Verney, M. Clavdianou, and C. Salakos, "Successful diagnosis and treatment of Dieulafoy's lesion with endoscopy and thermocoagulation in a full-term neonate: report of a case and literature review," Journal of Pediatric Surgery Case Reports, vol. 2, no. 5, pp. 250-253, 2014.

[4] Y. J. Lee, J. M. Oh, S. E. Park, and J. H. Park, "Successful treatment of a gastric Dieulafoy's lesion with a hemoclip in a newborn infant," Gastrointestinal Endoscopy, vol. 57, no. 3, pp. 435-436, 2003.

[5] E. Polonkai, A. Nagy, I. Csízy et al., "Pyloric atresia associated with Dieulafoy lesion and gastric dysmotility in a neonate," Journal of Pediatric Surgery, vol. 46, no. 10, pp. E19-E23, 2011.

[6] N. P. Rossi, E. W. Green, and J. D. Pike, "Massive bleeding of the upper-gastrointestinal tract due to Dieulafoy's erosion," Archives of Surgery, vol. 97, no. 5, pp. 797-800, 1968.
[7] Y. H. Koo, J. S. Jang, J. H. Cho et al., "Endoscopic injection treatment for gastric dieulafoy lesion in two newborn infants," The Korean Journal of Gastroenterology, vol. 46, no. 5, pp. 413417, 2005.

[8] Y. W. Lee, J. H. Shin, M. Y. Chang, and J. Y. Kim, "Endoscopic hemoclipping treatment for gastric Dieulafoy lesion in a newborn," Korean Journal of Pediatric Gastroenterology and Nutrition, vol. 14, no. 4, pp. 393-397, 2011.

[9] T. Gallard, "Aneurysmes miliares de l'estomac donnant lieu à des hematemesis mortelles," Bulletins et Mémoires de la Société Médicale des Hôpitaux de Paris, vol. 1, pp. 84-91, 1884.

[10] G. Dieulafoy, "Exulceratio simplex: l'intervention chirurgicale dans les hematemesis foundroyantes consecutive à l'exulceration simplex de l'estomac," Bulletin de l'Académie Nationale de Médecine, vol. 39, pp. 49-84, 1898.

[11] M. Itani, T. Alsaied, L. Charafeddine, and N. Yazbeck, "Dieulafoy's lesion in children," Journal of Pediatric Gastroenterology and Nutrition, vol. 51, no. 5, pp. 672-674, 2010.

[12] M. M. Linhares, B. H. Filho, V. Schraibman et al., "Dieulafoy lesion: endoscopic and surgical management," Surgical Laparoscopy, Endoscopy and Percutaneous Techniques, vol. 16, no. 1, pp. 1-3, 2006.

[13] D. Voth, "Zur Pathogenese ungerwóhnlischer, artellier mangendlutungen," Die Medizinische Welt, vol. 19, pp. 1095-1097, 1962.

[14] M. Baxter and E. H. Aly, "Dieulafoy's lesion: current trends in diagnosis and management," Annals of The Royal College of Surgeons of England, vol. 92, no. 7, pp. 548-554, 2010.

[15] W. Lim, T. O. Kim, S. B. Park et al., "Endoscopic treatment of dieulafoy lesions and risk factors for rebleeding," Korean Journal of Internal Medicine, vol. 24, no. 4, pp. 318-322, 2009. 


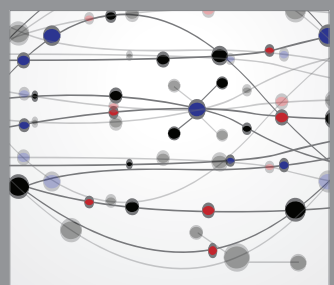

The Scientific World Journal
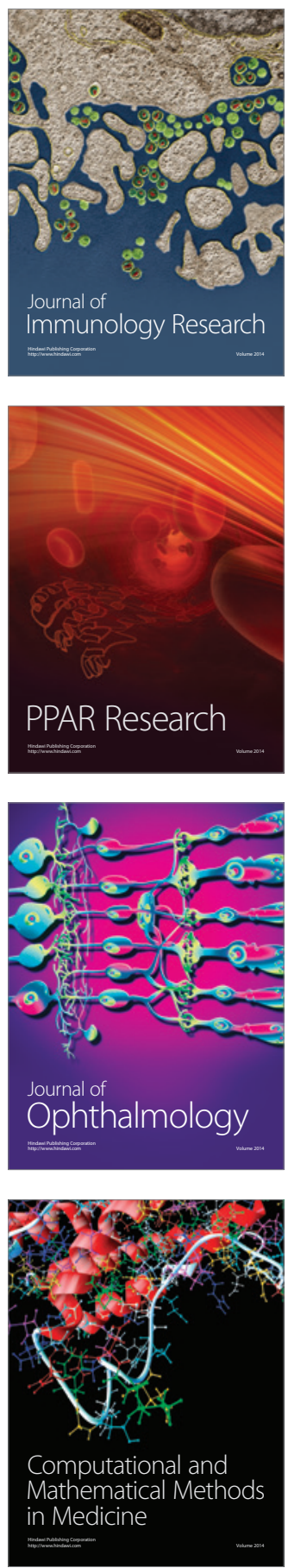

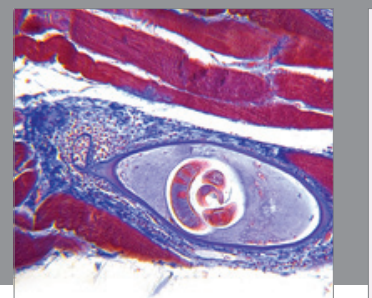

Gastroenterology

Research and Practice
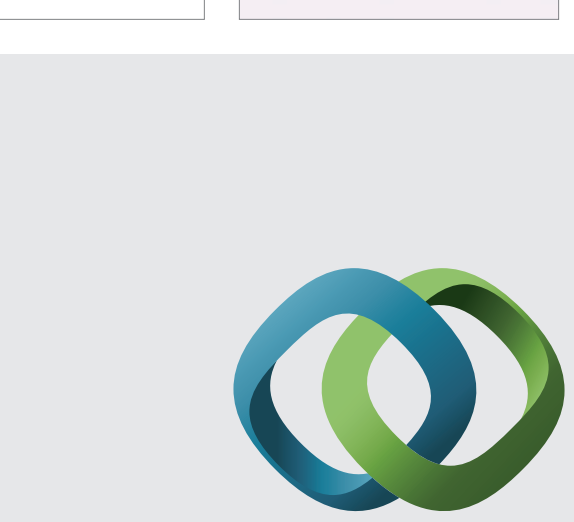

\section{Hindawi}

Submit your manuscripts at

http://www.hindawi.com
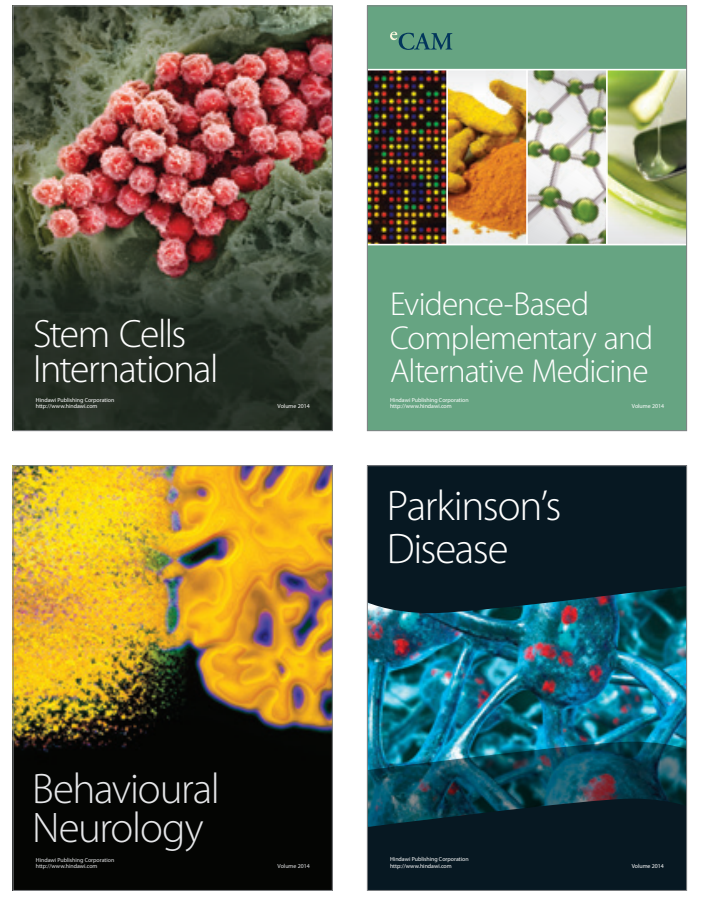
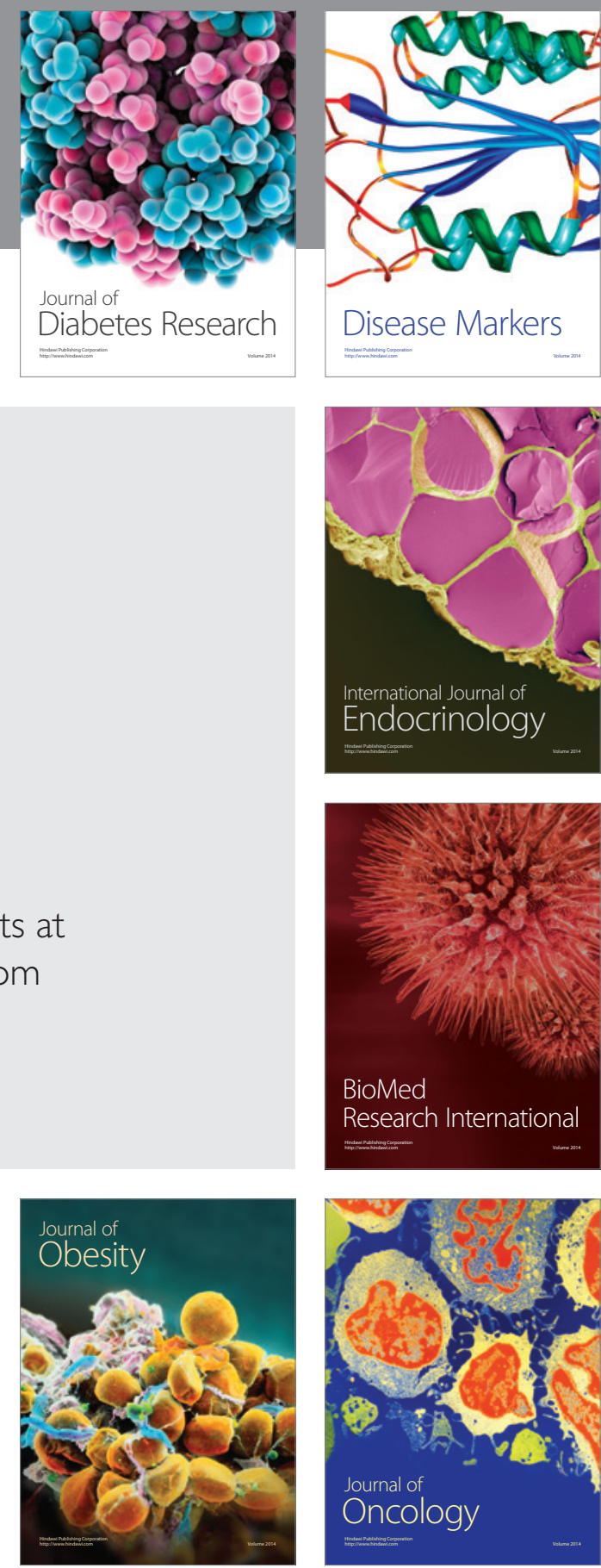

Disease Markers
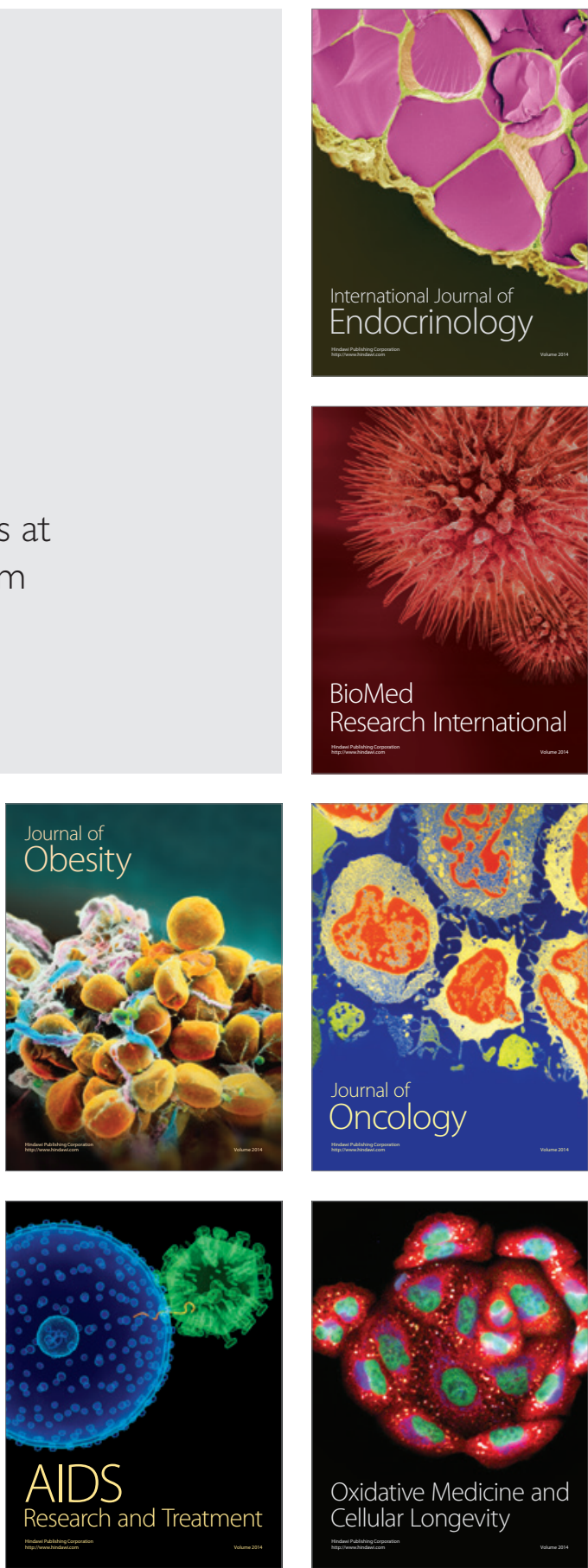